\title{
Narrativas e Imagens \\ Sobre Povos Indígenas e Amazônia: Uma Perspectiva Processual da Fronteira'
}

\author{
João Pacheco de Oliveira \\ Museu Nacional \\ Universidade Federal do Rio de Janeiro
}

Resumo: Este artigo está voltado para a compreensão das representações construídas sobre os indígenas amazônicos. Servindo-nos dos instrumentos de uma teoria da fronteira, procuramos romper com a descrição histórica generalizante, apontando a diversidade de temporalidades, narrativas e regimes que singularizam esta trajetória histórica das populações autóctones da Amazônia até o momento atual. Procuramos assim identificar os processos concretos pelos quais as populações autóctones vieram a relacionar-se com o contexto colonial e a serem inseridas na formação da nação brasileira e na economia mundial.

Palavras-Chave: Narrativas; temporalidades; povos indígenas; Amazônia; fronteira.

\footnotetext{
${ }^{1}$ Texto publicado originalmente em: Pacheco de Oliveira, João -"Narrativas e Imagens sobre povos indígenas e Amazonia: uma perspectiva processual da fronteira”. INDIANA 27, pgs. 19-46, Ibero-Amerikanisches Institut, Berlin, 2010.
} 


\title{
Narratives and Images On Indigenous Peoples and Amazon: A Procedural Perspective of Frontier
}

\begin{abstract}
This article aims to contribute to the understanding of representations of indigenous peoples in the Amazon region. Based on a theory of border, we attempt to break with a generalizing historical description, pointing out the diverse preliminaries, narratives and regimes that have distinguished the historical trajectory of authochthonous populations in the Amazon region up to the present day In so doing, we attempt to identify the tangible processes whereby authochthonous populations interacted with the colonial context and were integrated into the Brazilian nation and the global economy.
\end{abstract}

Keywords: Narratives; temporalities; Indigenous Peoples; Amazon; Border.

\section{Relatos e Imágenes Acerca de Indígenas y Amazon: Uma Perspectiva Procedimental de la Frontera}

Resumen: Este artículo se centra en la comprensión de las representaciones construídas sobre los pueblos indígenas amazónicos. Nos sirven los instrumentos de uma teria de la frontera, rompemos con la descripción histórica generalizante, señalando la diversidade de regímenes, narrativas y temporalidades que haga esta trayectoria histórica de los pueblos indígenas. Buscamos identificar los processos específicos mediante el cual las poblaciones indígenas há llegado a relacionar el contexto y a insertarse em la formación de la nación brasileña y em la economia mundial. frontera.

Palabras-clave: Narrativas; temporalidades; pueblos indígenas; Amazon; 
Frequentemente as interpretações sobre a parte brasileira da Amazônia não dão a devida importância a um fato primordial. É que a América Portuguesa não estava constituída por uma única, mas sim por duas colônias distintas: a do Brasil, cuja sede permaneceu em Salvador (BA) por mais de dois séculos, abrangendo da capitânia de São Vicente (São Paulo) ao Ceará, incorporando o litoral, a mata atlântica e se desdobrando para os sertões do rio São Francisco; e a do Maranhão e Grão-Pará, cuja sede foi a cidade de Belém, próxima a embocadura do rio Amazonas, tendo como seu hinterland toda a região configurada pelo enorme vale deste rio e de seus numerosos afluentes.

Não se trata de um detalhe da vida política-administrativa portuguesa, mas da instituição de dois modelos de colonização, com estratégias bastante diferentes de incorporação das populações autóctones e de utilização de recursos naturais, o que repercutiu no estabelecimento de unidades sociais com modos de organização e modalidades de auto representação diferentes.

Um instrumento analítico fundamental de que me sirvo neste ensaio histórico é a noção de fronteira, inspirada em formulações pioneiras de Roberto Cardoso de Oliveira (1978) e de Otávio Velho (1976). Em um trabalho posterior eu procurei sistematizar aquelas contribuições e fornecer alguns parâmetros para o delineamento de uma teoria da fronteira e de seus processos de expansão (Pacheco de Oliveira, 1979). Noções como a de "situação histórica" e de "regime tutelar", utilizadas ao longo do texto, decorrem do meu trabalho etnográfico com o povo indígena Ticuna (Pacheco de Oliveira, 1988), numa tentativa de explicitação de um instrumento analítico que interconectasse de maneira orgânica a observação etnográfica com um quadro histórico preciso.

$\mathrm{Na}$ investigação histórica aqui desenvolvida há um componente de pesquisa de imagens. Neste sentido o conteúdo que atribuo à noção de cenário corresponde menos à ideia sociológica de um setting e mais a de paisagem (enquanto utilizada na análise de pinturas), aproximando-se da categoria de "landscape" utilizada por alguns antropólogos de língua inglesa².

A comunicação que se segue, voltada basicamente para a compreensão das representações construídas sobre os indígenas amazônicos e a expansão desta fronteira, tem necessariamente implícita uma dimensão comparativa, estabelecendo em alguns pontos paralelos com o lugar que ocuparam as populações autóctones no modelo de colonização estabelecido na costa atlântica. Para a compreensão da singularidade da história da Amazônia é essencial entender as

${ }^{2}$ Vide, entre outros, Hirsch \& Hanlon, 1996. 
diferentes modalidades de fronteira que ocorreram no Brasil, com características e temporalidades distintas.

\section{A imagem da "última fronteira"}

Que imagens de Amazônia os brasileiros carregam dentro de si e afluem automaticamente ao seu espírito cada vez que esta palavra é mencionada? O que sabemos desse conjunto de representações que nos leva a agir e pensar sobre uma Amazônia real, a expressar ideias e conceitos sobre os seus primeiros habitantes, bem como sobre a sua história e a sua situação atual?

Tais imagens, apesar de estarem dentro de nós e as sentirmos como familiares, não foram de modo algum por nós produzidas. São rigorosamente exteriores e arbitrárias, convenções cujos pressupostos freqüentemente desconhecemos. Depositadas em nossa mente, resultam do entrechoque de concepções engendradas por gerações passadas, formuladas em lugares próximos ou distantes de nós. Mas são elas que dirigem nossas perguntas e ações, e muitas vezes governam nossas expectativas e emoções.

Para falar sobre isso precisamos iniciar não em 1500, nem em 1492 (chegada dos europeus na América) ou 1542 (primeira navegação dos espanhóis no rio Amazonas), mas no século XIX, em que foram moldadas a maior parte das idéias com que ainda hoje lidamos como se fossem naturais, intemporais, imotivadas. Pensadores do século XIX legaram representações artísticas e científicas que nos levam a pensar na Amazônia desde um prisma único, com imagens estereotipadas e idéias preconcebidas, compondo uma totalidade dada como inquestionável.

Segundo essas descrições - que ainda alimentam muitos mitos atuais - a Amazônia é o mundo das águas e da floresta, em que a natureza funciona como um sistema integrado e harmonioso, imperando de forma quase absoluta. É aquele lugar privilegiado do planeta onde se realizaria a mais perfeita expressão do primado da natureza sobre o homem, uma espécie de paraíso perdido que nos reporta ao cenário de uma terra antes do aparecimento do homem. Em suma, o império da natureza e o acanhamento da civilização, o planeta das águas e o deserto da história.

Nesse complexo de imagens a avaliação da natureza pode oscilar, ora mesquinha e decadente, ora magnífica e esplendorosa. Entre os que enfatizam a primeira direção sublinhando a adversidade do meio ambiente e a inadequada adaptação das espécies vivas (sobretudo do homem) àquele cenário, estariam as teorias sobre a degeneração do homem americano, inspiradas em Buffon e Cornelius De Paw3. Autores nacionais e estrangeiros pintaram em cores vívidas

3 Vide para uma descrição mais extensa dessas teorias Duchet, 1977. 
como a força da floresta avassalaria os homens e lhes imporia um destino inexorável 4 .

No segundo grupo entram outros pensadores, com posições radicalmente contrárias. O mais destacado foi Alexander Humboldt (1822) que, mesmo não circulando nas colônias portuguesas, expressou uma visão otimista, falando da Amazônia como um futuro "celeiro do mundo". Outros viajantes do rio Amazonas, como Bates e Agassiz, destacaram igualmente as potencialidades da região. Este último, em um artigo escrito em 1865, ironizava de maneira inclemente as repetitivas descrições (negativas) sobre as perspectivas do homem na Amazônia: "A opinião geral, com efeito, é que o clima do Amazonas é dos mais insalubres do mundo. Não há um só viajante que não o descreva de um modo assustador. É o país das febres, dizem todos" 5 . Na mesma linha Tavares Bastos em 1866, preocupado em assegurar um desejável fluxo de colonos estrangeiros para a região, apresentava o seu juízo definitivo: "Manaus tem uma reputação antiga de fertilidade, beleza e de excelência de clima. As margens do Solimões ou Alto Amazonas são perfeitamente habitáveis" (pg. 371).

Se existiam divergências quanto à potencialidade dessa natureza amazônica, não havia qualquer discordância quanto ao seu caráter majestoso nem quanto a pouca importância da parcela da humanidade que ali se localizava. Os naturalistas Spix e Martius (1981) estabeleceram um paralelo entre uma "natureza exuberante" e uma história nova, que mal então se iniciava. Elisée Reclus (1862), alguns anos depois, contrastou a importância da Amazônia na história da terra com a sua nulidade na perspectiva da história do homem. Euclides da Cunha (1976), à parte observações muito argutas sobre os usos e costumes locais, veio a reforçar essa visão sobre a ausência de história, ao comentar que "realmente, a Amazônia é última página, ainda a escrever, do Gênesis" (pg. 290), onde o homem "é ainda um intruso impertinente".

É preciso perceber que esse discurso é algo historicamente datado e que de maneira alguma se prestou apenas a essa região e a seus habitantes. O século XIX, sobretudo a sua segunda metade, é àquele em que a expansão colonial se deu com maior intensidade, colocando os exploradores europeus frente a frente com as populações autóctones de diversas partes do mundo. Em 1800 as potências européias controlavam 35\% da superfície do globo, em 1914 detinham 85\%. Edward Said, ao nos apresentar uma análise deste processo de expansão, conclui que jamais existiu anteriormente na história da humanidade um número tão elevado de colônias, implicando em uma desigualdade sem precedentes entre as unidades sociais e políticas de colonizadores e colonizados, algo desconhecido até no antigo Império Romano (Said, 1999).

4 Vide, entre outros, o romance O Inferno Verde, de Alberto Rangel (1907), que contou inclusive com um prefácio de Euclides da Cunha.

5 Jornal do Commércio, 18-05-1865. 
O tropos da natureza virgem, com vastos recursos ambientais, terra livre e despovoada de homens, é algo extremamente recorrente no imaginário dessa época. Os livros de viagem configuraram um gênero de conhecimento extremamente disseminado no século XIX na França, Inglaterra e Alemanha, do qual a famosa Bibliothèque Universelle des Voyages, de 1833, constitui apenas alguns dos mais de 200 títulos levantados sobre a América (Berthiaume, 1990). Isso não ocorre somente na América ou na Amazônia, mas na África, na Índia, na Oceania. Em primorosas ficções, autores como Conrad, Kipling e Melville, falaram dessas regiões distantes através de personagens e eventos relatados em seus romances e novelas, propagando extensamente e em língua inglesa imagens muito fortes sobre o mundo colonial.

Igualmente nas novas nações da América, surgidas de rupturas políticas com suas antigas metrópoles, ocorrerram processos internos de colonização. Foi o que aconteceu na parte oeste dos Estados Unidos. A natureza virgem, a ser subjugada e colocada a produzir riquezas (isto é, mercadorias) passou a ser concebida como uma fronteira sempre em movimento. Exemplifica isso a famosa tese de Frederick Jackson Turner, ligando a expansão para o oeste, a orientação religiosa dos pioneiros (movidos pela idéia de um "destino manifesto") e a consolidação de princípios igualitários na sociedade norte-americana ${ }^{6}$.

Também ocorreu no outro extremo do continente, ao sul do rio Bio-Bio no Chile e nos pampas da Araucânia na Argentina7. No próprio Brasil esse gênero discursivo alimentou uma produção de textos em alemão, onde os colonos de Santa Catarina e Rio Grande do Sul reproduziam em suas memórias e correspondências a saga do homem branco, relatando suas próprias experiências de heroísmo, sacrifício e dedicação (Brignol, 2002).

As descrições e análises, no entanto deslocavam-se de um a outro lugar sem precisar alterar a mesma retórica, freqüentemente traduzida na idéia "da última fronteira". Virgem, no caso, significava sem dono anterior, podendo ser livremente apossada. Sem reconhecer, portanto às populações autóctones um direito, exclusivo e precedente, aos territórios por eles antes ocupados.

Em um célebre texto datado de 1882 o pensador francês Ernst Renan (s/d) diz que as nações constroem o seu sentimento de unidade não só a partir de memórias, celebradas e reconhecidas, mas também com base em esquecimentos. Estes uma vez transformados em convenções, logo se tornam tão consensuais que sobre eles não se necessita falar. Os interesses das populações autóctones não foram de maneira alguma levados em consideração na expansão colonial nem na formação dos novos estados nacionais.

Nos primeiros esforços de levantamento de fontes e construção sistemática de uma história do Brasil, ainda nas décadas seguintes à Independência, o que houve

${ }^{6}$ Vide, entre outras obras deste autor, O Espírito Ocidental contra a Natureza: Mito, História e as Terras Selvagens, Rio de Janeiro, Campus, 1990. Para uma postura crítica ver Velho, 1975.

7 Vide Briones, \& Carrasco, 2000 e Bengoa, 2000. 
foi um confinamento dos indígenas aos capítulos iniciais da nossa história ${ }^{8}$. Nos trabalhos mais destacados do Instituto Histórico e Geográfico Brasileiro 9 - como a premiada tese de Von Martius (1845) e as minuciosas investigações históricas de Varnhagen (1978) - os indígenas localizados dentro dos limites territoriais nacionais foram abordados de forma totalmente desfavorável, considerados como expressão pura de primitivismo e simplicidade. Tais perspectivas eram apoiadas em reiteradas comparações com estados pré-colombianos anteriormente situados nos Andes e na América Central, possibilitando o enquadramento das populações autóctones da Amazônia nas formas mais simples de humanidade, sublinhando o seu completo distanciamento até mesmo de formas embrionárias de civilização.

\section{Representações sobre o primeiro encontro}

O que nos causa estranheza hoje é que as fontes coloniais disponíveis para o estudo dos indígenas, que foram lidas e utilizadas de um modo bastante exaustivo pelos pensadores do século XIX, não conduzem de maneira alguma a tais interpretações. O que os primeiros cronistas, Diego de Carvajal e Gaspar de Acuña (1945), relataram sobre a descida do rio Amazonas, respectivamente em 1542 e em 1639, foram populações extensas, aglutinadas em grandes povoações ribeirinhas, praticando diversas formas de cultivo e criatório, dispondo de numerosos guerreiros e eficientes estratégias de combate. Tratava-se de sociedades complexas e estratificadas, com formas políticas e manifestações religiosas bastante elaboradas. Um desses povos, descrito por Carvajal como verdadeiros senhores do rio, eram liderados por um grande chefe, cujo nome lhes ficou conhecido - Apariá.

Os registros atualmente feitos pelos arqueólogos reafirmam também a complexidade das sociedades pré-coloniais, comprovadas a partir do estudo circunstanciado de fragmentos de cultura material e de disposições espaciais (Heckenberger, 1996; Neves, Barreto \& McEwan, 2001).

O primeiro encontro entre os colonizadores europeus e as populações autóctones não ocorreu da mesma forma nas costas do litoral atlântico e no interior do vale amazônico. Enquanto no litoral os europeus recém-saídos das caravelas, abrigavam-se em montes e baías logo fortificadas, conseguindo realizar atos performáticos de sua força e poder, a narrativa de Carvajal e Acuña é bastante dramática, reconstituindo a viagem como uma sequência de combates e fugas frente a populações que lhes eram superiores em termos numéricos, logísticos e militares.

O registro histórico da chegada dos portugueses a Bahia, realizado na carta imediatamente enviada a El Rey por Pero Vaz de Caminha, escrivão da frota

\footnotetext{
8 Para uma critica do padrão historiográfico adotado em relação às populações autóctones, vide Pacheco de Oliveira, 2009. 9 Há uma aprofundada bibliografia sobre o tema, destacando-se, entre outros: Guimarães, 1988; Domingues, 1989; Guimarães, 1995; Kodama, 2005.
} 
comandada por Pedro Álvares Cabral, esteve perdido por mais de três séculos nos arquivos da metrópole. Só nas primeiras décadas do século XIX é que foi redescoberto e efetivamente recolocado em circulação pelos historiadores. No contexto da formação nacional, sobretudo no Segundo Império, veio a alimentar a imaginação de artistas como Vitor Meirelles, inspirando o famoso quadro $A$ primeira missa no Brasil, pintura que veio a ser acolhida mais tarde como um dos emblemas maiores da nacionalidade. Ali, em um evidente ritual de natureza política e ideológica, todo o protagonismo coube unicamente aos portugueses, que tomaram posse daquela terra de maneira pacífica e celebraram o seu deus, enquanto os autóctones eram apenas espectadores de uma cena que não entendiam, mirando com olhares que oscilavam entre o desinteresse e o encantamento.

\section{[IMAGEM 1 Vitor Meirelles - A Primeira Missa no Brasil (1861)]}

Os diários de viagem de Carvajal e Acuña não inspiraram registros semelhantes. A saga dos militares e religiosos espanhóis, açoitados pela fome, pelo desconhecimento do terreno e pela progressiva deterioração de sua tropa, só poderia expressar a frágil condição dos pretensos descobridores, não se adequando com facilidade ao mito do surgimento de uma nação $0^{10}$. A tentativa de criar através da pintura uma imagem celebratória da descoberta da Amazônia levou o governador do Pará, na primeira década do século XX, a encomendar ao artista Antonio Parreira uma tela que logo se tornou famosa.

Mas inversamente ao que ocorreu no registro referente à colônia Brasil, a pintura não expressava a centralidade da performance política dos colonizadores, que se distribuíam em posturas múltiplas face aos autóctones. A luz incidente na imagem desnuda de uma mulher indígena, para a qual os olhares dos europeus se dirigem vorazmente, vem a replicar o título dado ao quadro - A Conquista do Amazonas. O que o pintor sugere ao seu público, longe da celebração de um pacto para a formação de uma colônia ou de uma nação, é a exibição da fragilidade de meios dos colonizadores e os fins puramente egoísticos e particulares que os movem. Os elevados ideais da conversão religiosa e o projeto político imperial parecem submergir numa imagem de exploração e rapina.

[IMAGEM 2 Antonio Parreira - A Conquista do Amazonas (1906)]

\footnotetext{
10 Bem ao contrário, viria a estimular, em pleno século XX, uma reflexão cinematográfica sobre a loucura e os limites da humanidade, como na obra de Werner Herzog, Aguire, The Wrath of God. Sobre a importância dos fatores emocionais e de estados alterados da consciência na literatura e na etnografia dos viajantes na África; vide Fabian, 2000.
} 
Tal diferença na representação sobre como as duas colônias portuguesas na América foram integradas ao processo de construção de uma história e um imaginário nacional, no pós-Independência, já estava enraizada na própria história colonial precedente. A administração portuguesa não tratou essas duas regiões de maneira homogeneizadora, mas as instituiu em distintas colônias ultramarinas, que irão ter ritmos e configurações históricas diferenciadas.

Na colônia do Brasil os sítios ocupados pelos europeus iniciavam-se como fortificações e praças-fortes, que abrigavam enclaves comerciais e ampliavam-se para os sertões com a implantação de engenhos e plantações. Mais além dessas áreas protegidas vinham as fazendas para o criatório extensivo de gado. Olinda, Recife, Salvador e Rio de Janeiro, entre outras, foram cidades que seguiram essa estratégia política e arquitetônica, e não divergiram muito das cidades medievais. Num primeiro momento os índios, mobilizados ainda pacificamente, concorreram decisivamente para a construção das cidades, na edificação de igrejas, fortes e outras obras públicas (Pacheco de Oliveira \& Rocha Freire, 2007). Logo os cultivos voltados para a exportação passaram a demandar lavouras mais extensas, o que significaria a expansão territorial e maior mobilização de trabalho, estabelecendose então o choque com o projeto colonial. Os escravos indígenas, chamados então de "negros da terra" (Monteiro, 1994), foram progressivamente substituídos por escravos africanos nas grandes "plantations" de açúcar e algodão, dentro de um comércio triangular (Portugal, África e Brasil) que gerava lucros e tributos para a metrópole.

Ao contrário a exploração da Amazônia irá prosseguir, sobretudo pelas vias fluviais e por expedições pontuais, privilegiando a atividade extrativista e tendo um caráter temporário, materializada nas expedições para a coleta das drogas do sertão, a pesca do peixe-boi e a captura da tartaruga. Em sua quase totalidade essa produção estava voltada para a exportação, não supondo necessariamente o estabelecimento no interior de praças-fortes e núcleos urbanos. A ocupação do interior ocorria apenas pela implantação de aldeamentos missionários, unidades produtoras unicamente dependentes do trabalho indígena e, portanto, da aceitação por estes da conversão e da atuação dos agentes religiosos externos.

\section{O indígena como recurso fundamental}

O fator econômico fundamental para a ocupação da Amazônia, tanto para as expedições extrativistas como para o estabelecimento de aldeamentos missionários, foi o trabalho indígena, chamado pelo padre Antonio Vieira de "ouro vermelho”, sobre o qual foi erigida toda a riqueza da região (Hemming, 1978). É na 
procura e no controle desse fator essencial de produção, para o qual não foi criada qualquer outra alternativa exitosa até a década de 1870, que colonos, religiosos e autoridades mantiveram acirradas disputas e também chegaram a uma composição entre seus interesses.

$\mathrm{O}$ indígena, à diferença do negro, não devia legalmente ser objeto de escravidão, mas poderia sofrer um descimento, sendo deslocado coletivamente de seu lugar de origem para outro de maneira a ali ser aldeado, receber assistência religiosa e vir a trabalhar em atividades de interesse dos colonos ou da administração. Tais aldeias eram as fornecedoras de mão de obra tanto para as fazendas do litoral quanto para as expedições extrativistas que percorriam o interior da Amazônia em busca das drogas do sertão. Eram também ai recrutados os indígenas que por longos períodos eram destinados a realização de obras públicas (construção de fortificações, caminhos, igrejas) ou tarefas especialmente pesadas, assim como serviam em atividades militares (em guerras e revoltas).

As tropas de resgate, por sua vez, percorriam os sertões, supostamente voltadas para libertar índios cativos destinados à antropofagia, mas na realidade estabelecendo (por captura ou compra aos próprios índios). Era ainda permitida a declaração de guerra justa contra um povo indígena ou comunidade local, os prérequisitos para isso sendo muito amplos, abrangendo desde atos lesivos contra os colonos (incluindo mortes, roubos e furtos) até a simples recusa em receber educação religiosa. Das guerras justas, assim como da ação das tropas de resgate, resultava um mercado paralelo onde a escravidão indígena era aceita como legal. Ainda que aplicada por períodos longos (quinze anos), tal condição era conceituada como fato temporário e justificada seja por razões pedagógicas seja para pagar os custos de tais expedições.

Contra alguns povos, como os Tupinambás do Maranhão, os índios do rio Negro, os Mura e os Mundurucu foram dirigidas verdadeiras guerras de extermínio. Fontes coloniais estimam que, em apenas 5 anos, de 1621 a 1626, um capitão-mor do Pará tenha aniquilado ou conduzido ao cativeiro cerca de 500 mil indígenas (Pacheco de Oliveira \& Rocha Freire, 2007). O movimento liderado por Ajuricaba, que durou de 1723 a 1727, foi uma das poucas revoltas indígenas que a história registrou, terminando com uma violenta repressão aos Manaós. O impacto disso foi ainda mais agravado, pois entre 1743 e 1750 grassou uma epidemia de varíola no rio Negro, estimando-se em 40 mil o número de mortos no estado do Grão Pará. Após o lançamento de uma devassa e ao cabo de uma longa e cruenta campanha militar, em 1775 as aldeias dos índios Mura foram tomadas ou destruídas e a população restante considerada pacificada (Coutinho, s/d).

Se as ações militares, bem como a propagação de doenças, serviu para extinguir muitos povos e interferir de forma grave em suas condições de reprodução sócio-cultural, reduzindo inclusive fortemente o seu contingente populacional, é importante ter presente que não alterou os pressupostos econômicos da ocupação da Amazônia, que continuou a ter no indígena o fator 
básico tanto para o povoamento quanto para qualquer modalidade efetiva de geração de renda.

Em termos político-administrativos ocorreu uma mudança devido à nova política delineada para a região pelo Marques de Pombal, priorizando a demarcação das fronteiras e um controle direto do Estado sobre a população indígena. Movida por preocupações geopolíticas de assegurar a soberania portuguesa em todo o território ocupado e estabelecer o pleno domínio destas autoridades sobre a população, Pombal limitou drasticamente o poder das ordens religiosas. As antigas aldeias foram transformadas em povoados e sedes de comarcas, cabendo a autoridades laicas encarregar-se de sua gestão.

A vida civil passou a ser a melhor escola para os indígenas e as autoridades laicas os instrutores mais adequados para transformar os indígenas em cidadãos. Na legislação para isso elaborada, o chamado Diretório dos Índios (1757), era claramente adotada uma perspectiva assimilacionista, com a imposição do português como língua oficial e a proibição de uso de línguas nativas ou da língua geral. O casamento interétnico era igualmente incentivado, bem como revogada a proibição de residência de não índios nas antigas aldeias.

A criação e o aparelhamento institucional de núcleos urbanos no interior implantou uma nova base para o domínio político sobre a região. Mas ao contrário da pretendida emancipação dos indígenas e a ampliação de sua participação na vida civil, o que ocorreu na prática foi o agravamento das formas de exploração da mão de obra indígena, com os chamados diretores atuando como agenciadores privados dos trabalhos executados pela população autóctone, agindo sem qualquer fiscalização ou comedimento. O resultado da aplicação de tal política foi a consolidação de redes particulares de clientela, que atuarão na mobilização do trabalho e no comércio, numa antecipação de circuitos econômicos que se estenderão até o ciclo da borracha. A economia regional foi desarticulada e até mesmo muitos povoados sofreram decréscimos populacionais com a fuga de moradores das antigas aldeias. Apesar disso toda e qualquer atividade na região continuará a depender exclusivamente - e por mais de um século - do trabalho indígena.

Durante nove anos, de 1783 a 1792, Alexandre Rodrigues Ferreira (1971), um filósofo da natureza formado na Universidade de Coimbra, viajou pela Amazônia acompanhado de dois desenhistas realizando para o governo português um levantamento minucioso das riquezas da região. O extenso resultado de suas pesquisas, publicadas muito espaçadamente ao correr de diferentes contextos históricos, evidencia que - apesar das guerras, epidemias e da política assimilacionista - a presença indígena continuou a ser dominante na região e que as características culturais de tais povos eram exibidas na vida cotidiana. Alguns desenhos mostram isto com nitidez (Carvalho Junior, 2000). 
[IMAGENS 3, 4, 5 e 6 Índio Cambeva - Índio do Rio Branco - Índio Mura - Índio do Rio Branco]

\section{A formação da nação e o índio bravo}

Eis-nos de volta ao século XIX. José Bonifácio de Andrade e Silva, figura central no primeiro reinado, destacava que era apenas através de "meios brandos e suassórios" que o índio viria a integrar-se na nascente sociedade brasileira. No Brasil independente não havia mais lugar para a decretação de guerras justas contra povos indígenas específicos.

Banir das políticas de Estado a possibilidade de execução de ações bélicas oficiais voltadas contra os indígenas era uma tomada de posição de bastante significação. Naquele momento a população do país montava a 3, 6 milhões (incluindo, sem qualquer distinção, os índios já batizados e que viviam em contato regular) e era calculado em cerca de 800 mil o número de índios bravos. É para estes que, a partir daí, deveria estar voltada à atenção do Estado e da elite dirigente, produzindo-se uma completa rotação em relação às políticas coloniais, que antes tiveram como seu foco a produção do índio cristianizado.

É dentro desse jogo de imagens e representações que veio a surgir e ganhar grande significação o indianismo, transformado em símbolo de unidade da jovem nação. O índio do passado foi reabilitado, dignificado em seus valores e motivações, bem com justificadas as acusações que recebia na vida cotidiana (cruel, traiçoeiro, preguiçosos, etc). Poetas e romancistas, como Gonçalves Dias e José de Alencar, serviram-se de instituições e palavras indígenas para celebrar o destino da nação brasileira que surgia, em uma oposição nativista aos colonizadores portugueses (dos quais o país estava em vias de se separar). Mas a tão festejada imagem do 
índio não se aplicaria de forma alguma ao presente ${ }^{11}$. Os indígenas reais, apenas expressariam os últimos alentos, a lenta agonia dos bravos guerreiros do passado, cantados em prosa e verso.

O projeto de nação que estava sendo gestado indicava para as populações autóctone a via de inserção na sociedade brasileira através de estruturas tutelares. Primeiramente, ainda na Regência e no Império, apoiadas na ação de missionários católicos e na instituição do real padroado. Depois, já na República, com a formação de uma agência especializada, inspirada em concepções evolucionistas (positivismo comteano) e em princípios hierárquicos da vida militar e do serviço público.

No Império do Brasil - e sobretudo no segundo reinado - foi posta em marcha uma homogeneização de estruturas administrativas e de formas de representação da nação. As representações sobre o índio assumiram uma forma única, focalizando-o sempre enquanto o índio bravo. O tapuio, o caboclo, o índio colonial foram totalmente esquecidos e pouco depois declarados inexistentes. Nas décadas seguintes à Lei de Terras (de 1850), as províncias do nordeste consideraram extintos os antigos aldeamentos, seja por vacância dessas terras, seja pela mestiçagem e suposta descaracterização dos seus habitantes.

As populações indígenas da Amazônia igualmente passaram a ser pensadas tão somente segundo as imagens produzidas para os índios bravos, isto é, como primitivos habitantes das fronteiras internas da nação, exteriores aos circuitos econômicos e sociais. Ou seja, ou coletividades virtualmente perigosas, remetidas aos estágios mais rudimentares da civilização; ou pessoas com parca capacidade de adaptação ao mundo contemporâneo, demandando um olhar complacente, totalmente dependente de uma mediação tutelar e protetora.

Rondon considerava os povos indígenas como formas de humanidade que se encontravam nos mais rudimentares estágios evolutivos. Em termos de religião e de princípios gerais estariam no estado fetichista, não sendo conveniente, através da catequização, forçá-los a passar abruptamente para as formas religiosas monoteístas. Para que pudessem vir a ser parte do Brasil, só seria cabível uma "proteção leiga e fraternal" que lhes permitisse uma lenta e espontânea evolução ${ }^{12}$. Rondon atuou, sobretudo na atração e pacificação de povos ditos isolados ${ }^{13}$.

Em termos de imagens e representações sobre o indígena o SPI não inovou, mas apenas deu seguimento a uma reversão ocorrida no pós-Independência (já comentada anteriormente). Para o indigenismo rondoniano, o índio era um ser primitivo, que ainda desconhecia o homem branco, sendo sempre pensado como ameaçado de extinção por sua difícil adaptação ao mundo contemporâneo. A

\footnotetext{
${ }^{11} \mathrm{O}$ próprio Gonçalves Dias deixava claro que os fatos e personagens que narrava se reportavam exclusivamente ao passado, ao "povo americano, agora extinto". Para uma análise mais detida do indianismo nas artes, vide Pacheco de Oliveira, 2009. ${ }_{12}$ Para uma investigação sobre o Serviço de Proteção ao Indígena/SPI vide Souza Lima, 1995.

${ }_{13}$ Frequentemente tais índios já haviam sido de algum modo atacados ou ameaçados por seringueiros ou por outras frentes extrativistas, e foi justamente em função disso se tornaram arredios e avessos ao homem branco. A atribuição da condição de isolados raramente correspondia a um isolamento real.
} 
atenção do indigenismo se dirigiu exclusivamente ao índio bravo (na acepção colonial de aquele que não era batizado nem participava regularmente de circuitos de troca ou de trabalho com os regionais), sobre o qual se propunha a executar uma tutela protecionista, que o viesse a incorporar como um brasileiro. As intenções de José Bonifácio e as concepções dos indianistas podiam ser facilmente percebidas, re-fraseadas no jargão positivista de um missionarismo laico.

\section{[IMAGEM 7 - Rondon entre os indígenas de Mato Grosso (Major Thomas Reis)]}

Pacificando as tribos aguerridas, colocando-as sob tutela federal e impondo a paz nas relações entre brancos e índios, Rondon e seus seguidores muito contribuíram para abrandar as violências praticadas contra os indígenas no interior do país. Raramente, porém conseguiram preservar o habitat destes povos ou assegurar o controle sobre seus antigos territórios, logo incorporados ao mercado de terras e apropriados por interesses privados.

\section{A economia da borracha e a conquista da Amazônia}

O primeiro censo realizado no Brasil, ocorrido em 1872, nos fornece evidências quanto à presença indígena no Brasil durante o Segundo Reinado ${ }^{14}$. Ao contrário da crença propagada pelo indianismo e transformada em política pública pelos governos provinciais, o censo demonstrou o não desaparecimento dos indígenas na costa atlântica. Em alguns estados, como o Ceará, os indígenas chegavam a representar $10 \%$ da população total. Na Amazônia os resultados do censo apontavam uma distância ainda maior entre os dados estatísticos e a consciência da elite imperial. O censo nacional de 1872 indicava claramente que $64 \%$ da população do Amazonas era classificada como caboclos (isto é, índios e seus descendentes) ${ }^{15}$.

Na Amazônia mesmo um autor como Tavares Bastos, que considerava os indígenas uma "raça decaída" e preconizava a miscigenação (biológica), o livre

14 Vide Pacheco de Oliveira, 1999.

${ }_{15}$ Embora o uso atual do termo caboclo tenha hoje em dia uma carga étnica menos acentuada, não trazendo uma associação tão imediata com indígenas, é importante lembrar que assim não ocorria no século XIX. Assim na tradução francesa do censo de 1872 é claramente distinguido o caboclo (traduzido por "indien", isto é, índio) do mestiço (que no censo é referido por "pardo" e traduzido para "métis"). 
comércio e o trabalho assalariado como mecanismos para aperfeiçoamento da população autóctone, citava dados que contradiziam sua visão sobre a pouca importância dos indígenas naquele contexto. Segundo ele na década de 1860 haveria cerca de 17 mil índios "vivendo em tribus" (isto é, de forma autônoma) nas planícies do Alto Amazonas (op. cit., pg. 357), o que se aproximava bastante da população da região na época.

Até o início do ciclo da borracha, que no Amazonas ocorreu entre 1870 e 1911, o índio ainda era maioria. Antes do último lustro do século XIX a atividade seringalista não apresentava grandes rupturas em relação ao modo de colonização vigente desde os alvores do século XVII, com as expedições para coleta de "drogas do sertão”. Embora alguns autores (Moreira Neto, 1988) atribuam principalmente à política assimilacionista do Diretório dos índios a transformação da população autóctone de maioria em minoria, isto não é de maneira alguma correto. Os cenários apresentados pelos viajantes, com os seus relatos e paisagens, mostra a predominância da presença indígena, o que o censo de 1872 veio a ratificar. Inclusive o índio continuou a ser a mão de obra básica nos primeiros seringais no Baixo Amazonas.

A extraordinária expansão da atividade de extração da borracha pelo vale amazônico, ocorrida no final da década de 1870, foi sustentada pela demanda crescente e pelos altos preços do produto no mercado internacional. Todo o processo foi comandado de Londres e Nova York por agentes financeiros, que estabeleceram seus representantes em Belém e Manaus, cujas casas exportadoras controlavam uma miríade de rede de créditos, que se estendiam aos mais distantes seringais do Madeira, do Purus e do Alto Amazonas.

A diferença radical, contudo residia na escala e na modalidade de articulação comercial em pauta (casas aviadoras e bancos estrangeiros), o que implicava em uma pressão muito distinta em termos de volume da produção, intensidade do trabalho e extensão das áreas afetadas. Para responder a uma demanda crescente e a preços em elevação foram trazidos para a Amazônia milhares de nordestinos, que seriam transformados em coletores de borracha mediante esquemas de trabalho compulsório (a escravidão por dívida e o monopólio comercial do barracão).

A mão de obra que veio a garantir essa produção não decorreu de qualquer política oficial de estímulo ou fiscalização desse processo. Foram milhares de brasileiros pobres, recrutados no interior do nordeste, em regiões afetadas pelas secas, que foram transformados em cabeças de frente e suporte básico desta expansã $0^{16}$. A busca do látex, o "ouro negro", levou os seringueiros a penetrar no mais recôndito da floresta, entrando em conflito com as populações indígenas que ainda ali mantinham suas formas próprias de vida e uma relativa autonomia face aos comerciantes e aos caboclos ribeirinhos.

16 Vide Furtado, 1969 e Benchimol, 1965. 
Para esta nova modalidade econômica o indígena foi apenas um empecilho, a ser tratado (paradoxalmente) como um invasor, um perigoso intruso a ser expulso para bem longe. O seu extermínio, através de expedições punitivas chamadas de correrias, representava de fato uma solução mais corriqueira para o problema. Foi através da capilaridade dessa imensa rede de créditos que comandava um enorme exército de homens, que os índios bravos que habitavam na Amazônia - e que constituíam a maioria daqueles 800 mil estimados - tiveram as suas terras atravessadas pelas estradas de seringa e invadidas por colocações de seringueiros. Foi nesse processo que desapareceram inúmeras etnias, dadas como extintas no início do século XX.

Mesmo mais tarde, nas áreas de rentabilidade comparativamente menor e que implicavam em maiores custos de transporte, os índios continuaram a ser importantes na extração de borracha, sobretudo nos chamados seringais de caboclo (Pacheco de Oliveira, 1979). Outros povos, como os Ticunas, os Cashinauás e os Miranha, foram incorporados como trabalhadores pela frente extrativista, funcionando como mão de obra essencial tanto para a coleta do látex quanto para as atividades de apoio (remeiros, guias, trabalhos agrícolas, etc) no seringal. Se escaparam de um extermínio imediato, passaram a sofrer uma forma de escravidão ainda mais arbitrária e brutal do que aquela imposta aos seringueiros brancos, com profundas repercussões sobre a sua cultura, formas de sociabilidade e volume demográfico ${ }^{17}$.

\section{Do Regime do Seringal ao Regime Tutelar}

Com a entrada maciça da produção de borracha dos seringais de cultivo da Malásia no mercado internacional, já ao início da segunda década do século XX, os preços do látex caíram progressivamente, instalando-se uma grave crise na economia amazônica. Fora breves oscilações favoráveis, a produção de borracha na região a partir de 1911 prosseguiria em declínio. A articulação com o mercado internacional veio à torna-se exígua, mas as relações de produção mantiveram-se tais quais (com o aviamento, o monopólio comercial do barracão, o endividamento dos trabalhadores), operando no entanto com produtos de menor valor (pescado, peles e madeira) voltados para os mercados locais ou regionais. Com exceção do curto período dos chamados "soldados da borracha" (1941-45), iniciativa governamental de reativar a produção gomífera por razões estratégicas, não ocorreram novos fluxos de trabalhadores para os seringais nem para as antigas áreas produtoras.

A frente extrativista da borracha não se extinguiu, nem se desarticulou bruscamente, ela apenas tornou-se estacionária e começou a integrar-se muito lentamente aos circuitos econômicos locais. Após 1912 a expansão dos seringais

${ }_{17}$ Vide Pacheco de Oliveira, 1988; Aquino \& Iglesias, 1994; e Iglesias, 2010. 
através do vale amazônico foi interrompida, acarretando uma diminuição da pressão sobre as populações autóctones, sobretudo nas violências resultantes da penetração na floresta e do contato com povos relativamente isolados. Isso representou um freio tão ou mais decisivo na invasão de suas terras quanto à criação do SPI e a definição de uma nova política indigenista pelo governo brasileiro, fato que ocorreu concomitante com a crise da borracha.

O impacto da atuação do indigenismo rondoniano sobre os povos indígenas da Amazônia foi bastante diferenciado, em algumas situações marcante e decisivo, em outras apenas tópico e eventual. Este foi o caso do Amazonas, Acre, Roraima e Amapá, que configuravam a maior parte da região ${ }^{18}$. Em outros estados, no entanto, Rondon e seus seguidores estiveram mais atuantes, como no Mato Grosso e Rondônia no início do século XX, e na região do alto Xingu via a Fundação Brasil Central (Menezes, 2000). Apesar da visibilidade nacional e internacional do SPI, os seus próprios ideólogos observaram que, na primeira metade do século $\mathrm{XX}$, registrou-se ainda a desaparição de mais 87 etnias, sendo 37 dessas de povos classificados como isolados (Ribeiro, 1970).

Passado o boom da borracha, a existência cotidiana dos indígenas na Amazônia não conheceu mais nenhum impacto similar, que os afetasse de maneira tão geral, profunda e integrada. Em um levantamento realizado nos arquivos do SPI na década de 1950 a população indígena foi estimada entre 68 e 99 mil índios (Ribeiro, 1957, op. cit), o que representava aproximadamente 0,2\% da população brasileira. Foram relacionadas 150 etnias, cerca de $1 / 4$ das quais a agência não possuía qualquer informação. $O$ perfil desta população estava composta fundamentalmente por micro-etnias, que perfaziam mais da metade desse universo e eram representadas por povos com menos de 100 integrantes,. No pólo oposto às etnias com população superior a 2000 membros eram muito poucas. A imagem que se poderia inferir dos indígenas brasileiros era então de unidades sociais muito pequenas, fortemente ameaçadas e que apenas conseguiam sobreviver devido à tutela oficial.

Nos anos 70, com o chamado "milagre brasileiro" (Davis, 1978), foi delineado um ambicioso plano viário interligando entre si e com a capital federal as cidades localizadas na fronteira, projeto que viria consorciado com a criação de colônias do INCRA para assentamento de lavradores sem terra, provenientes de outras regiões do país (sobretudo do nordeste). Se transformado em realidade esse planejamento certamente viria a afetar profundamente as condições de vida dos indígenas, fato porém que não ocorreu devido à conjuntura econômica internacional. No plano interno a agência indigenista, sob o argumento de antecipar-se aos impactos desse planejamento, conseguiu mobilizar alguns recursos para estabelecer uma infraestrutura mínima e tornar-se mais presente na Amazônia.

${ }_{18}$ Para uma análise da atuação do SPI na região amazônica, vide: Mello, 2009; Moreira Santos, 2009; Iglesias, 2010, op.cit. 
Uma conjuntura política mais favorável, nos anos 80 e 90, trouxe para os indígenas melhores perspectivas. O processo de identificação de terras indígenas (Pacheco de Oliveira, 2006), embasado na realização de inúmeros estudos antropológicos e históricos, permitiu que em alguns casos as populações autóctones viessem a definir seus limites territoriais como eram anteriormente ao apogeu da borracha e à penetração da frente seringalista. Antes do final do século $\mathrm{XX}$ grandes áreas que abrigavam populações numerosas estavam demarcadas e destinadas exclusivamente à posse e usufruto pelos indígenas (com a indenização e transferência dos ocupantes não indígenas), como ocorreu com a Terra Yanomami, as áreas Ticunas, o alto e médio Rio Negro, o vale do Javari, as áreas Kayapó, etc (Grankow, 2002).

Uma avaliação do perfil demográfico dos povos indígenas da Amazônia realizada na década de 1990 permitia detectar fortes mudanças face aos dados apresentados pelo SPI nos anos $1950^{19}$. As sociedades indígenas de porte médio (entre 200 e 2000 membros) já constituíam maioria (70 em 136) e representavam quase um terço (28\%) do total de população indígena. Por sua vez as microsociedades representavam uma parte pequena do total $(3,3 \%$ da população indígena) e em que as etnias maiores (acima de 2000 integrantes) incorporavam $68,3 \%$ da população indígena total.

\section{O Contexto Pós-Tutela}

A nova carta constitucional, promulgada em 1988, veio trazer modificações no quadro legal relativo aos indígenas. A perspectiva assimilacionista, com a concepção correlata dos indígenas como vivendo unicamente uma condição transitória, foram pontos derrogados. Os indígenas tiveram pela primeira vez reconhecido o direito as suas formas próprias de organização, assim como a sua plena capacidade jurídica, podendo ser representados seja por suas autoridades tradicionais, seja por associações livremente constituídas (Pacheco de Oliveira, 2008).

Nos anos seguintes mais de duas centenas de organizações indígenas foram criadas na chamada Amazônia Legal, passando a pautar-se pela administração de projetos de etnodesenvolvimento e de assistência diferenciada. Os recursos da cooperação internacional, sobretudo aqueles voltados para fomento à proteção ambiental, foram em boa parte carreados diretamente para as ações locais através das organizações indígenas. Os territórios habitados pelos índios passaram a ser vistos igualmente como unidades de conservação. A ação governamental relativa aos indígenas deixou de estar centralizada em uma única agência (FUNAI), subordinada a um único ministério (Justiça), para estar distribuída também em diferentes ministérios (Educação, Saúde e Meio Ambiente).

19 Vide Pacheco de Oliveira, 1999. 
Hoje os índios da Amazônia têm seus interesses representados não pela agência indigenista, mas por organizações (como a FOIRN, o CIR, o CIM, o CGTT, o CGTSM, a UNI-Acre, o CIVAJA, entre muitas outras) que os representam em diferentes níveis, desde o local e o étnico até o regional e o nacional. Hoje as organizações indígenas articulam-se em rede e sua coordenação geral é executada pela COIAB, sediada em Manaus, possuindo representações próprias em conselhos diretores de muitas agências governamentais (Pacheco de Oliveira, 2010).

As frentes de expansão posteriores à da borracha tiveram impactos setoriais e intermitentes, acarretando, no entanto, ameaças a alguns povos e áreas específicas. Assim foi o caso dos garimpos na área dos Cinta-Largas, dos Yanomami e Makuxi, em Roraima, em Pari-Cachoeira, no rio Negro; da madeira entre os Kayapós do Pará e os Marubo do vale do Javari; e atualmente da soja em Mato Grosso, Rondônia e Roraima.

Paralelamente surgiram na Amazônia outras alternativas econômicas para os não indígenas, marcadas não mais pela economia rural, mas centralizadas nos núcleos urbanos maiores (especialmente Manaus com a instituição da zona franca), caracterizadas por intensa atividade industrial, de serviços e de turismo. Transformados em novos estados, Roraima, Acre, Amapá e Tocantins, vieram a criar estruturas administrativas próprias, inclusive instalando universidades. Com uma aceleração do êxodo rural, as capitais cresceram muito, passando a abrigar a maioria da população dos estados.

A diversidade cultural e lingüística atual dos povos indígenas na Amazônia ainda representa um patrimônio de valor inestimável. Além das notícias sobre tradições autóctones de grande complexidade cultural, que estão sendo investigadas pelos arqueólogos, há uma impressionante vitalidade nas manifestações sócio-culturais contemporâneas, que colocam desafios para as ciências humanas talvez ainda maiores do que os do passado.

Segundo os dados do IBGE relativos ao censo de 2001 os indígenas no Brasil como um todo são cerca de 734 mil, com uma taxa anual de crescimento $(10,8 \%)$ muito superior a da população brasileira $(1,6 \%)$. Estudos recentes sugerem que a elevada taxa de crescimento dos indígenas reflete não apenas a melhoria das condições de saúde, mas também a existência de processos de re-classificação identitária por parte de segmentos da população brasileira, permitindo a autoclassificação como indígenas de comunidades, famílias e indivíduos antes recenseados como "pardos" (Paoliello, 2010). As expectativas para o censo de 2010 é de que o contingente de indígenas pelo menos dobre, ultrapassando os 1,5 milhões.

Torna-se necessária à incorporação de novas dimensões para pensarmos sobre os povos e culturas indígenas contemporâneas. Segundo o censo de 2001 a metade da população indígena tem hoje também alguma forma de residência (em tempo parcial, provisória ou definitiva) em pequenas cidades do interior ou mesmo 
nas grandes capitais ${ }^{20}$, o que lhes coloca novos problemas e desafios, a serem respondidos por associações de características variadas. Há atualmente que levar em conta a existência de alguns milhares de jovens indígenas que já concluíram ou estão em vias de concluir cursos universitários (Nascimento, 2009; Aires, 2009; Santos, 2007).

À diferença de um passado recente, a identidade de indígena é hoje objeto de elevada auto-estima, não só por parte de líderes políticos e religiosos, como expressão de um suposto tradicionalismo, mas também pelos mais jovens, como expressão de processos contemporâneos ligados à globalização. As identidades indígenas resultam de uma referência coletiva às origens (vividas sempre de modo variável, por referência à cultura) e são nesse sentido importantes âncoras intelectuais e afetivas no contexto atual.

A atualização e recuperação de valores e dignidades ancestrais não é uma possibilidade aberta somente aos que nasceram em unidades sociais autônomas, fora dos postos ou das terras indígenas. As gerações nascidas nas reservas, assim como os descendentes de índios coloniais (tapuios, caboclos, índios de missões religiosas) as reivindicam igualmente.

Um fenômeno importante e característico da atual conjuntura indígena brasileira é o ressurgimento de afirmações identitárias por parte de coletividades que, segundo uma leitura restritiva de fontes governamentais, aparentemente estariam assimiladas. Longe de ser um fenômeno exclusivo da faixa atlântica, isso ocorre extensamente também em outras regiões do país e inclusive fortemente na Amazônia. Se na década de 80 os índios Ticunas eram os únicos com reivindicações étnicas no Alto Solimões, hoje muitas outras coletividades se definem igualmente como indígenas, adotando outras denominações (como Cocamas, Cambevas e Caixanas) e, juntamente com os Ticunas, constituindo os indígenas como a maioria da população rural da região.

Hoje ser índio não equivale a exemplificar a representação do primitivo, nem preencher as expectativas de observadores externos quanto à manutenção atual de algum costume ou símbolo específico, mas sim a uma demarcação de natureza política, que fundamenta direitos perante o Estado e a opinião pública, cujos componentes culturais e emblemas étnicos irão variar de acordo com os diferentes contextos históricos e as distintas tradições culturais priorizadas. São índios todos aqueles que integram coletividades que se reivindicam como possuindo uma descendência pré-colombiana. Como é explicitado pela convenção 169 da OIT, nos últimos anos acolhida com força de lei no Brasil devido a sua ratificação pelo Senado e pela Presidência da República, o fator decisivo para uma afirmação identitária não pode ser outro que a via das auto-definições.

2o Ver neste sentido os estudos desenvolvidos pelo Projeto Nova Cartografia Social da Amazônia, coordenado por Alfredo Wagner Berno de Almeida, na Universidade Estadual do Amazonas (UEA). 
O que procuramos fazer nesse artigo foi, servindo-nos dos instrumentos de uma teoria da fronteira, romper com a descrição histórica generalizante que considera que o contato interétnico e a expansão da fronteira traz em si um processo inexorável de extinção das populações autóctones. O que o investigador da história dos indígenas da Amazônia pode fazer é explicar como tais representações homogeneizadoras surgiram, a que interesses, contextos e grupos sociais estiveram associadas.

Por outro lado procuramos identificar os processos concretos pelos quais as populações autóctones vieram a relacionar-se com o contexto colonial e vieram a ser inseridas na formação da nação brasileira e na economia mundial. A perda de controle dos povos indígenas sobre seus territórios foi um fenômeno relativamente recente, que veio de 130 anos atrás, com a expansão da borracha pelo vale amazônico e a implantação de uma formação social baseada em uma rede de clientelas e aviamentos, característica do regime do seringal. Foram as marcas ainda vivas na memória das populações locais, assim como em usos sociais e na relação com o meio ambiente, que vieram a fundamentar a identificação e reconhecimento de terras indígenas, colocadas em prática por um regime tutelar nas últimas décadas. No atual contexto pós-tutela, a tendência à perda territorial, ao declínio demográfico e a ocultação de suas próprias identidades e tradições, aparecem como tendências já revertidas, mas coexistindo com problemáticas desafiadoras, carregadas de novas ameaças e potencialidades.

Em suma, discutindo modelos de colonização e mostrando a variabilidade dessas formas de fronteira no tempo e no espaço, bem como identificando as estruturas políticas que concretamente as implementaram, a nossa intenção aqui foi de apontar a diversidade de temporalidades, narrativas e regimes que singularizaram esta trajetória histórica das populações autóctones da Amazônia até o momento atual. 


\section{Referências Bibliográficas}

Aires, Max Maranhão P.(org). Escolas Indígenas e Políticas Interculturais no Nordeste Brasileiro. Fortaleza, EdUECE, 2009.

Aquino, Terri Vale de \& Iglesias, Marcelo P. Os Kaxinawá do Rio Jordão, Rio Branco, Comissão Pró-Índio, 1994.

Benchimol, Samuel. O cearense na Amazônia - Inquérito antropogeográfico sobre um tipo de migrante. Rio de Janeiro, SPVEA, 1965.

Bengoa, Jose. Historia del pueblo Mapuche, Santiago, Lom Eds, 2000.

Berthiaume, Pierre. L'aventure américaine au XVIIIe siècle. Du voyage à l'écriture. Otawa/Paris/Londres, Les Presses de l’Université d'Otawa, 1990.

Brignol, Liliane Moreira. "Olhos azuis sobre o cocar: representações e fronteiras étnicas na colônia Blumenau (1850-1880)". Tese de Doutoramento, Universidade Federal Fluminense, 2002.

Briones, Claudia \& Carrasco, Morita. Pacta sunt servanda: Capitualaciones, convênios y tractados com los indígenas em Pampa y Patagonia (Argentina, 1742 e 1878), IWGIA, Buenos Aires, 2000.

Carvalho Junior, Almir Diniz. Do índio imaginado ao índio existente. A construção da imagem do índio na Viagem Filosófica de Alexandre Rodrigues Ferreira. Campinas, UNICAMP, 2000.

Coutinho, Antonio Carlos da Fonseca. Notícias da voluntária redução de paz e amizade da feroz nação do gentio Mura nos anos de 1784, 1785 e 1786, Rio de Janeiro, Realto, s/d.

Cunha, Euclides da "Amazônia: Terra sem História”. In: Um Paraíso Perdido. Reunião dos Ensaios Amazônicos. Petrópolis (RJ), Editora Vozes, 1976.

Davis, Shelton. Vítimas do Milagre: o desenvolvimento e os índios do Brasil. Rio de Janeiro, Zahar, 1978.

Domingues, Heloísa Maria Bertol. A noção de Civilização na visão dos construtores do Império. (A revista do Instituto Histórico e Geográfico Brasileiro: 1838-1850/6o). Dissertação de mestrado, Programa de PósGraduação em História, UFF, 1989.

Duchet, Michèle. Anthropologie et histoire au siècle des lumières: Buffon, Voltaire, Rousseau, Helvetius, Diderot. Paris, Flammarion, 1977. 
Fabian, Johannes. Out of Our Mind: Reason and madness in the exploration of Central África. Frankfurt, Frankfurt University Press, 2000.

Furtado, Celso. Formação Econômica do Brasil, São Paulo, Companhia Editora Nacional, 1969.

Grankow, Márcia (org). Demarcando terras indígenas: Experiências e desafios de um projeto de parceria. Brasília, GTZ/FUNAI, 2002.

Guimarães, Lucia Maria Paschoal. "Debaixo da imediata proteção de Sua Majestade Imperial. O Instituto Histórico e Geográfico brasileiro (1838-1889)”. Revista do IHGB, no. 388, 1995.

Guimarães, Manoel L. Salgado. "Nação e civilização nos trópicos: o Instituto Histórico e Geográfico brasileiro e o projeto de uma história nacional". Estudos Históricos, 1 (1):5-27, 1988.

Hagen, Victor Wolfgang Von. South America Called Them. Explorations of the great naturalists. New York, Alfred A. Knopf, 1945.

Heckenberger, Michael J. War and Peace in the Shadow of Empire: Sociopolitical change in the Upper Xingu of Southeastern Amazonia, A.D. 1250-20oo. Ph. D. Tesis. Pittsburgh. University of Pittsburgh, 1996.

Hemming, John. Red Gold: The conquest of the Brazilians Indians. London. Macmillan, 1978.

Hirsch, Eric \& O` Hanlon, Michael (eds). Anthropology of Landscape: Perspectives on place and space. Oxford, Clarendon Press, 1996.

Humboldt, Alexander. Ensayo politico sobre el reino de la Nueva España. Paris, s. e., t. i., 1822.

Iglesias, Marcelo Piedrafita. Os Kaxinawá de Felizardo: correrias, trabalho e civilização no Alto Juruá. Brasília, Paralelo 15, 2010.

Kodama, Kaori. Os filhos das brenhas e o Império no Brasil: a etnografia do IHGB (1840-1860). Programa de Pós-Graduação em História Social, PUCRJ, Rio de Janeiro, 2005.

Mello, Joaquim. SPI - A Política Indigenista no Amazonas, Manaus, Edições Governo do Estado, 2009.

Menezes, Maria Lucia Pires. Parque Indígena do Xingu: a construção de um território estatal. Campinas/São Paulo, Ed. UNICAMP/Imprensa Oficial, 2000.

Monteiro, John Manuel. Negros da terra: Índios e bandeirantes nas origens de São Paulo. São Paulo, Companhia das Letras, 1994. 
Moreira Santos, Ana Flávia. Conflitos Fundiários, Territorialização e Disputas Classificatórias. Autazes (AM), primeiras décadas do século XX. Tese de doutoramento em Antropologia Social, Rio de Janeiro, PPGAS, 2009.

Moreira Neto, Carlos de Araújo. Índios da Anazônia, de Maioria a Minoria (175o1850). Petrópolis, Vozes, 1988.

Nascimento Rita Gomes. Rituais de Resistência: Experiências Pedagógicas Tapebas. Tese de doutoramento em Educação, Natal, UFRN, 2009.

Neves, Eduardo; Barreto, Cristiana and McEwan, Colin. "Introduction” In: Culture in Nature in Ancient Brazil, Colin McEwan, Cristiana Barreto and Eduardo Neves, London, The British Museum, 2001.

Oliveira, Roberto Cardoso de. A Sociologia do Brasil Indígena. Tempo Brasileiro, Rio de Janeiro, 1978.

Pacheco de Oliveira, João. "O caboclo e o brabo: Notas sobre duas modalidades de força-de-trabalho na expansão da fronteira amazônica no século XIX”. Encontros com a Civilização Brasileira, 11, 1978.

- O "Nosso Governo": Os Ticunas e o Regime Tutelar, São Paulo/Brasília, Editora Marco Zero/CNPq, 1988.

. "Entrando e saindo da mistura: os índios nos censos nacionais". In: Ensaios em Antropologia Histórica. Rio de Janeiro, Editora da UFRJ, 1999.

e Rocha Freire, Carlos Augusto da. A presença indígena na formação do Brasil. Brasília, MEC, 2007.

"As mortes do indígena no Império do Brasil: o indianismo, a formação da nacionalidade e seus esquecimentos" In: Cultura Política, Memória e Historiografia. Cecília Azevedo, D. Rollemberg, P. Knauss, M.F. Bicalho e S.V. Quadrat (orgs). Rio de Janeiro, FGV Editora, 2009.

. "O Nascimento do Brasil: A revisão de um paradigma historiográfico". Anuário Antropológico 2009-I, pp. 9-40. Rio de Janeiro: Tempo Brasileiro.

CAAAP/Contra Capa, 2006.

. Hacia una Antropologia del Indigenismo. Lima/Rio de Janeiro, . "Sem a tutela, uma nova moldura de nação" In 20 Anos da Constituiçãa de 1988. R. G. Oliven, M. Ridenti e G.M. Brandão (orgs). São Paulo, ANPOCS, 2008. 
. "Regime tutelar e globalização: um exercício de sociogenese dos atuais movimentos indígenas no Brasil". In: Tradições \& Modernidades. D. Aarão Reis, H. Mattos, J. Pacheco de Oliveira, L.E. S. Moraes e M. Ridenti (orgs). Rio de Janeiro, FGV Editora, 2010.

Paoliello, Tomas P. O. Revitalização étnica e dinâmica territorial em Mirandiba: alternativas contemporâneas à crise da economia sertaneja. Rio de Janeiro, Dissertação de Mestrado, PPGG/IGEO, UFRJ, 2010.

Rangel, Alberto. O Inferno Verde. Rio de Janeiro, Typ. Arrault, 1907.

Reclus, Elisée. "Le Brésil et la colonisation”. Revue des Deux Mondes, Paris, 15/06/1862.

Renan, Ernst. Qu'est-ce qu'une Nation? Et autres essais politiques. Paris, Presses Pocket, s/d.

Ribeiro, Darcy. Os índios e a civilização. A integração das populações indígenas no Brasil moderno. Rio de Janeiro, Civilização Brasileira, 1970.

Rodrigues Ferreira, Alexandre. Viagem filosófica pelas capitanias Grão-Pará, Rio Negros, Mato Grosso e Cuiabá. Rio de Janeiro, Conselho Federal de Cultura, 1971.

Said, Edward. Cultura e Imperialismo. Companhia das Letras, São Paulo, 1999.

Santos, Gersem Luciano dos. O Índio Brasileiro: O que você precisa saber sobre os povos indígenas no Brasil de hoje. Brasília, SECAD/MEC, 2007.

Souza Lima, Antonio Carlos. Um grande cerco de paz. Poder tutelar, indianidade e formação do Estado no Brasil. Petrópolis, Vozes, 1995.

Tavares Bastos, Aureliano. O Valle do Amazonas [1866]. Companhia Editora Nacional, Brasiliana 106, São Paulo, 1937.

Turner, Frederick Jackson. O Espírito Ocidental contra a Natureza: Mito, História e as Terras Selvagens, Rio de Janeiro, Campus, 1990.

Varnhagen, Francisco Adolfo de. História Geral do Brasil antes de sua separação e independência de Portugal. São Paulo, Melhoramentos, 1978, [1854], 3 vols.

Velho, Otávio Guilherme. Frentes de Expansão e Estrutura Agrária. Zahar, Rio de Janeiro, 1970.

1976.

. Capitalismo Autoritário e Campesinato. Zahar, Rio de Janeiro, 
von Martius, Carl Friedich Philipe. 'Como se deve escrever a história do Brasil'. Revista do Instituto Histórico e Geográfico Brasileiro, 6 (24), pp. 381-403.

von Spix, Johann Baptiste \& von Martius, Carl Friedich Phillipp. [1917-1820] Viagem pelo Brasil. Rio de Janeiro, Imprensa Nacional, 1981. 